of adaptations out of the natural selection of undirected variations, to use my colleague's language, may prove to be a dogma quite as unsupported by facts as the Lamarckian dogma of the inheritance of acquired characters. I long ago pointed out that a very large number of new characters in the hard parts of mammals are adaptive in direction from the beginning; I am very far from saying that all new characters are adaptive in direction; I only make this statement as to those characters I have had the opportunity of repeatedly observing.

I now challenge the zoologists to produce a single instance of a series of animals in which adaptive characters are being accumulated through the selection of undirected variations, $i$. e., of variations which are thoroughly mixed up, in which there is no law evident. Such a series has never been produced by any one. Of course $I$ bar from this challenge orthogenic changes of character under environmental influences. I refer to the pure Darwinian hypothesis. The hypothesis is still as Darwin left it, an ingenious working theory, awaiting either experimental evidence or evidence of any kind. How long this assumption will pass muster as based on observation it is hard to say. We await some paleontological Weismann who will smite it hip and thigh as the zoological Weismann smote Lamarck's assumption.

While the "philosophic zoologist" of to-day has made his choice, the philosophic paleontologist has also made his choice. The latter certainly does not find direction in the old teleologic sense, but quite as certainly he finds no evidence of such fortuity as will justify the use of the word undirected as furnishing materials for natural selection. The materials for natural selection are furnished by the ensemble of an enormous number of characters, each of which is a unit pursuing its independent history and fluctuating and mutating and moving in direct lines under laws which the philosophic paleontologist has proof of, but totally fails to understand. Consequently he assumes the agnostic position that there is some principle, or principles of direction, or better-to use Professor Morgan's own words
- "unknown agencies," still to be discovered other than the principle of order coming out of fortuity.

\section{Henry Fairfield Osborn}

NELSON'S LOOSE LEAF ENCYCLOPEDIA.

To the EDitor of ScIEnce: In February an article was published in Nelson's "Loose Leaf Encyclopedia" upon the Messina-Reggio earthquake, the authorship of which was credited to Mr. Frank A. Perret and myself. In justice to Mr. Perret, however, it should be stated that he had nothing whatever to do with the preparation of the article beyond furnishing the one item pertaining to the height of the "tidal" wave at Messina which is duly credited to him. The insertion of Mr. Perret's name as joint author was done by the publishers of the encyclopedia without my knowledge or consent, but thus far I have been unable to obtain any correction of their error.

E. O. Hover

New YoRK,

May 11, 1909

\section{SCIENTIFIC BOOKS}

General Physics. By Henry Crew. New York, The Macmillan Co. 1908.

A Text-book of Physics. Edited by A. WILMer DufF. Philadelphia, P. Blakiston's Son \& Co. 1908.

The publication of these two excellent textbooks designed for college classes in physics illustrates the general dissatisfaction among college professors of physics with both existing text-books and accepted methods. There are many difficulties inherent in the teaching of physics and there are many points concerning which the best teachers are to a certain degree undecided. As physics is taught at the present time in most American colleges the time devoted to it is one year during each week of which there are three hours of lectures or class work, accompanied by five or six hours of laboratory work. In this time a student is supposed to cover the field of elementary mechanics, properties of matter and physics proper, including heat, light, etc. Within recent years a demand has arisen for textbooks which should have more or less refer- 